\title{
A Facile Route for Preparation of High-Performance Hierarchical Porous Carbons for Supercapacitor Electrodes
}

\author{
Lili Wang ${ }^{*}$, Miaomiao Jia, Wenqi Lu, Kunlong Yang, Junqin Fan, Gang Liao, Jianguo Yu* \\ College of Environment and Chemical Engineering \& State Key Laboratory of Hollow-Fiber \\ Membrane Materials and Membrane Processes, TianjinPolytechnic University, Tianjin 300387, PR \\ ChinabCollege \\ *E-mail: wanglili09.29@163.com, hh_y1118@hotmail.com
}

doi: $10.20964 / 2016.07 .27$

Received: 31 March 2016 / Accepted: 7 April 2016 / Published: 4 June 2016

\begin{abstract}
In this work, a facile route for preparation of high-performance hierarchical porous carbons from starch was described. The hierarchical porous carbons with developed micropores and mesopores were prepared, and the pore size was distributed at 2, 9 and $13 \mathrm{~nm}$. The high-performance porous carbons with specific capacity of $221 \mathrm{~F} / \mathrm{g}$ was obtained when the mass ratio of starch to zinc nitrate was 1:1 and the carbonization temperature was $800{ }^{\circ} \mathrm{C}$. It also possessed excellent specific capacitance retention about $96.4 \%$ of the initial value even after 5000 cycles, and the higher capacitance retention of $88.7 \%$ was obtained when the current density changing from 0.2 to $2 \mathrm{~A} / \mathrm{g}$. The pore structure and the electrochemical performance could be tuned by changing the reaction conditions. The experimental results suggested the hierarchical porous carbons could be an ideal candidate for supercapacitor applications.
\end{abstract}

Keywords: Starch, Hierarchical porous carbons, Supercapacitor, Specific capacity

\section{$\underline{\text { FULL TEXT }}$}

(C) 2016 The Authors. Published by ESG (www.electrochemsci.org). This article is an open access article distributed under the terms and conditions of the Creative Commons Attribution license (http://creativecommons.org/licenses/by/4.0/). 